\title{
Histomorphological spectrum of prostatic lesions and their correlation with serum prostate-specific antigen level
}

\author{
Rashid $N^{1}$, Dutta $U C^{2}$, Rahman $M L A^{3}$, Hassan $S W^{4}$ \\ Received on 14 $4^{\text {th }}$ June 2019; editorial approval on 10 $10^{\text {th }}$ January 2020
}

\begin{abstract}
Background: Prostate Specific Antigen (PSA) estimation is elevated in patients with prostate enlargements including prostatic diseases, surgical procedures, benign hyperplasia and prostatic malignancy. A significant increase of PSA has been correlated with prostatic cancer and as such the same parameter has been widely used in the diagnosis and management of prostatic cancer. Objective: The objective of the study was to determine the relationship between serum PSA levels and histological findings in biopsy specimens of prostatic lesions. Materials and methods: This study includes patients planned for prostatectomy. Blood samples were collected preoperatively and tested for PSA. Histology of the tissue samples collected after Trans Urethral Resection of Prostate (TURP) were studied and the relationship with PSA analyzed. The study pertains to the utility of PSA assay in different Prostatic lesions including carcinoma of Prostate. Results: 71 patients were included in the study. There were 59(83.10\%) benign cases, 7(9.86\%) cases of Prostatic Intraepithelial Neoplasia (PIN) and 5(7.84\%) cases of Adenocarcinoma (Adenoca) of the prostate. Serum PSA values were analyzed in different prostatic lesions like; Nodular Hyperplasia of Prostate (NHP), High-Grade Prostate Intraepithelial Neoplasia (HGPIN), Adenocarcinoma, etc. Conclusion: The study showed a statistically positive correlation between histological diagnosis and serum PSA. In all cases of malignancy, Gleason score was correlated with serum PSA values. However, the present study did not reveal any correlation between the two variables.
\end{abstract}

Keywords: Gleason's score; carcinoma; prostatitis.

\section{INTRODUCTION}

An approach to the diagnosis of prostate cancer has changed radically in recent years with the introduction of the PSA estimation, by doing an Ultrasound Scan Test (USG) and by Fine Needle Aspiration Cytology (FNAC)/ biopsy of the Prostate. $^{1,2}$

PSA is a glycoprotein which is secreted exclusively by the prostatic epithelium. It is not a tumour specific antigen as it reacts with the prostatic material in benign and malignant tissues. PSA is expressed in significant quantity by the cancer tissues compared to benign conditions. The normal level values in healthy males are usually $<4 \mathrm{ng} / \mathrm{ml}$ at an average. ${ }^{3,4}$ Serum PSA levels above the reference range have been reported in $50 \%$ of the men with stage A prostate cancer, in $80 \%$ with stage $\mathrm{B}$ disease and $100 \%$ with stage $\mathrm{C}$ and $\mathrm{D}$ disease. In a healthy 60 yrs old man with no evidence of prostatic carcinoma, the serum PSA concentration increases by approximately $3.2 \%$ per year (normal average:0.04 ng/ $\mathrm{ml}$ ). The utilization of age-specific ranges is useful in predicting the survival outcomes in Asian men., ${ }^{5,6}$ The study aims to evaluate histomorphological features of different prostatic

\footnotetext{
Address of Correspondence:

${ }^{1}$ Consultant Pathologist

Mobile: +918472838896

Email: nazninrashid786@gmail.com

${ }^{2}$ Director, Lab and Blood Bank (Corresponding author)

Mobile: +919435042865

Email: duttaumch@gmail.com

${ }^{3}$ Medical Director

Mobile: +919954345345

Email: rahmanhospitals@gmail.com

${ }^{4}$ Consultant Urologist

Rahman Hospitals Pvt. Ltd., VIP Road, Six-Mile,

Khanapara, Guwahati, Assam, India
}

Cite this article as: Rashid N, Dutta UC, Rahman MLA, Hassan SW. Histomorphological spectrum of prostatic lesions and their correlation with serum prostate-specific antigen level. Int J Health Res Medico Leg Prae 2020 July;6(2):15-20. DOI 10.31741/ ijhrmlp.v6.i2.2020.3 
lesions, classify them in different categories based on morphology and correlate those lesions with serum PSA level, including correlation of prostate-specific antigen levels with Gleason's score in malignant cases.

\section{MATERIALSAND METHODS}

The present study is a cross-sectional one. Seventy-one cases of prostatic biopsies received in the Pathology Department of Rahman Hospitals Pvt. Ltd. were included in the study along with their pre-operative serum PSA levels. All the patients who had undergone prostatectomy along with their pre-operative serum prostate-specific antigen levels were included as an inclusion criterion. Whereas non-compliant patient, autolyzed biopsy materials; specimens not properly labeled and cases where serum PSA un-available are excluded from the study.

Biopsy samples were processed for Formalin-Fixed and Paraffin-Embedded (FFPE) technique and stained routinely with Haematoxylene and Eosin (H \& E) stain. Special Stains, e.g., Ziehl Neelsen and Mucicarmine were used whenever required.

Specific variables were defined for prostate biopsies during the collection and analysis of the data. Every case was reported by a pathologist and findings were noted for all variables using a proforma. The cases were reviewed by a second pathologist, wherever indicated. The diagnosis was made using the variables. The diagnosis was then further correlated with the pre-operative serum prostate-specific antigen levels. The estimation of PSA was done quantitatively by a chemiluminescence method. Standard reference values were considered for the age of the patient.

Histomorphological details, histological diagnosis, Gleason score and serum PSA data were statistically analyzed. The distribution of study variables concerning diagnosis was observed and chi-square test and Pearson's Correlation between histological diagnosis and serum PSA levels were analyzed. Results were considered statistically significant if the p-value was less than 0.05 .

\section{RESULTS}

Seventy-one patients admitted for prostate enlargements were included for the present study. Serum PSA level was estimated in all the cases. Distributions of prostate lesions concerning age and histomorphological features were analyzed and their correlation with serum PSA levels was evaluated in this study.

In this study, out of total cases $(\mathrm{N}=71) ; 59(83.10 \%)$ cases were benign followed by premalignant and malignant cases comprising of $7(9.85 \%)$ and $5(7.04 \%)$ respectively.

Table 1 Distribution of different histological diagnosis of prostate $(\mathrm{N}=71)$

\begin{tabular}{|c|c|c|c|c|}
\hline Histological diagnosis & Frequency & Percentage & Total & $\mathbf{N}=71$ \\
\hline \multicolumn{4}{|l|}{ Benign } & \\
\hline NHP & 45 & $63.38 \%$ & \multirow[t]{2}{*}{$59(83.10 \%)$} & \\
\hline NHP with chronic prostatitis & 9 & $12.68 \%$ & & \\
\hline NHP with basal cell hyperplasia (BCH) & 2 & $2.82 \%$ & & \\
\hline NHP with Granulomatous Prostatitis (GP) & 3 & $4.23 \%$ & & \\
\hline \multicolumn{3}{|l|}{ Premalignant } & \multirow{4}{*}{$7(9.85 \%)$} & \\
\hline HGPIN & 7 & $9.86 \%$ & & \\
\hline \multicolumn{3}{|l|}{ Malignant } & & \\
\hline Adenoca (acinar type) & 4 & $5.63 \%$ & & \\
\hline Adenoca (mixed acinar and ductal type) & 1 & $1.41 \%$ & & \\
\hline Total & 71 & $100 \%$ & & \\
\hline
\end{tabular}

The study reveals that out of the total prostate lesions, 45(63.38\%)cases were of nodular hyperplasia followed by NHP with chronic prostatitis (9 cases) and high-grade prostate intraepithelial neoplasia comprising of 7 cases. NHP with granulomatous prostatitis was seen in 3 cases; NHP with Basal cell hyperplasia was seen in 2 cases and Carcinoma Prostate was seen in $5(7.04 \%)$ cases. 
Table 2 Distribution of histological variables in benign lesions $(\mathrm{n}=59)$

\begin{tabular}{|l|l|l|l|}
\hline Histological variables & Present & Absent & Total \\
\hline Papillary infoldings & $56(94.92 \%)$ & $3(5.08 \%)$ & $\mathrm{n}=59$ \\
\hline Cystically dilated glands & $56(94.92 \%)$ & $3(5.08 \%)$ & \\
\hline Corpora Amylacea & $46(77.97 \%)$ & $13(22.03 \%)$ & \\
\hline Basal cells & $59(100 \%)$ & 0 & \\
\hline Basal cell hyperplasia & $2(3.39 \%)$ & $57(96.61 \%)$ & \\
\hline Granuloma & $3(5.08 \%)$ & $56(94.91 \%)$ & \\
\hline Adenosis & $34(57.63 \%)$ & $25(42.37 \%)$ & \\
\hline
\end{tabular}

In this study, among the benign cases $(\mathrm{n}=59)$, the most predominant histological variable was basal cells which were seen in all the benign cases. Other variables like papillary infoldings and cystically dilated glands were each seen in 56
(94.92\%). Corpora amylacea was seen in $46(77.97 \%)$ cases. Basal cell hyperplasia was seen in 2(3.39\%) cases, granulomas were seen in $3(5.08 \%)$ cases and Adenosis in 34 (57.63\%) cases.

Table 3 Distribution of histological variables in premalignant lesions (HGPIN) $\quad(n=7)$

\begin{tabular}{|l|l|l|l|}
\hline Histological variables & Present & Absent & Total \\
\hline Nuclear atypia & $7(100 \%)$ & 0 & $\mathrm{n}=7$ \\
\hline Single cell layer & $3(42.86 \%)$ & $4(57.14 \%)$ & \\
\hline Central necrosis & $2(28.57 \%)$ & $5(71.43 \%)$ & \\
\hline Mitosis & $1(14.29 \%)$ & $6(85.71 \%)$ & \\
\hline
\end{tabular}

In this study, nuclear atypia was observed in all cases of HGPIN. Other variables like single cell layer, central necrosis and mitosis were seen in $3(42.86 \%), 2(28.57 \%)$ and 1 $(14.29 \%)$ respectively.

Distribution of histological variables in malignant cases $(n=5)$ : Out of 5 cases of carcinoma $(n=5)$, infiltrative glands, single-cell layer, nuclear atypia, mitosis, central necrosis and adjacent PIN were seen in all the $5(100 \%)$ cases. Histological variables like crystalloids and papillary structure each were seen only in $1(20 \%)$ case.

Distribution of Gleason score in different histological diagnosis $(n=5)$ : In this study, out of 5 cases of prostate carcinoma $(n=5)$, Gleason score 6 was more frequently encountered, comprising of $2(40 \%)$ cases, followed by Gleason score of 7, 8 and 9 comprising each of $1(20 \%)$ case.

Table 4 Different histological diagnosis according to different cut-off values of Serum PSA level (N=71)

\begin{tabular}{|c|c|c|c|c|}
\hline \multirow[t]{2}{*}{ Histological diagnosis } & \multicolumn{3}{|c|}{ Serum PSA(ng/ml) } & \multirow[t]{2}{*}{ Total } \\
\hline & $<4$ & $4-10$ & $>10$ & \\
\hline \multicolumn{5}{|l|}{ Benign } \\
\hline NHP & $44(61.97 \%)$ & $1(1.41 \%)$ & & $45(63.38 \%)$ \\
\hline NHP with chronic prostatitis & 0 & $9(12.68 \%)$ & & $9(12.68 \%)$ \\
\hline NHP with BCH & $1(1.41 \%)$ & $1(1.41 \%)$ & & $2(2.82 \%)$ \\
\hline NHP with GP & $3(4.23 \%)$ & 0 & & $3(4.23 \%)$ \\
\hline \multicolumn{5}{|l|}{ Premalignant } \\
\hline HGPIN & 0 & 0 & $7(9.86 \%)$ & $7(9.86 \%)$ \\
\hline \multicolumn{5}{|l|}{ Malignant } \\
\hline Adenoca (Acinar type) & 0 & 0 & $4(5.63 \%)$ & $4(5.63 \%)$ \\
\hline $\begin{array}{l}\text { Adenoca } \\
\text { (mixed acinar and ductal type) }\end{array}$ & 0 & 0 & $1(1.41 \%)$ & $1(1.41 \%)$ \\
\hline Total & $48(67.61 \%)$ & $11(15.49 \%)$ & $12(16.90 \%)$ & $71(100 \%)$ \\
\hline
\end{tabular}


Out of total cases $(\mathrm{N}=71)$, serum PSA level $<4 \mathrm{ng} / \mathrm{ml}$ was seen predominantly in NHP followed by NHP with GP and NHP with BCH cases respectively. A serum PSA level of 4$10 \mathrm{ng} / \mathrm{ml}$ was seen in NHP with CP followed by NHP and NHP with BCH each comprising of 1 (1.41\%) cases. Serum PSA level $>10 \mathrm{ng} / \mathrm{ml}$ was seen only in premalignant and malignant conditions; HGPIN ( $\mathrm{p}$ value $<0.05, \mathrm{x}^{2}$ test).

Correlation between serum PSA and Gleason score $(n=5)$ : In our study, there was statistically no correlation between Gleason score and serum PSA level in all cases of carcinoma $(\mathrm{n}=5)(\mathrm{r}=-.258 \mathrm{p}$-value $=0.676)$.

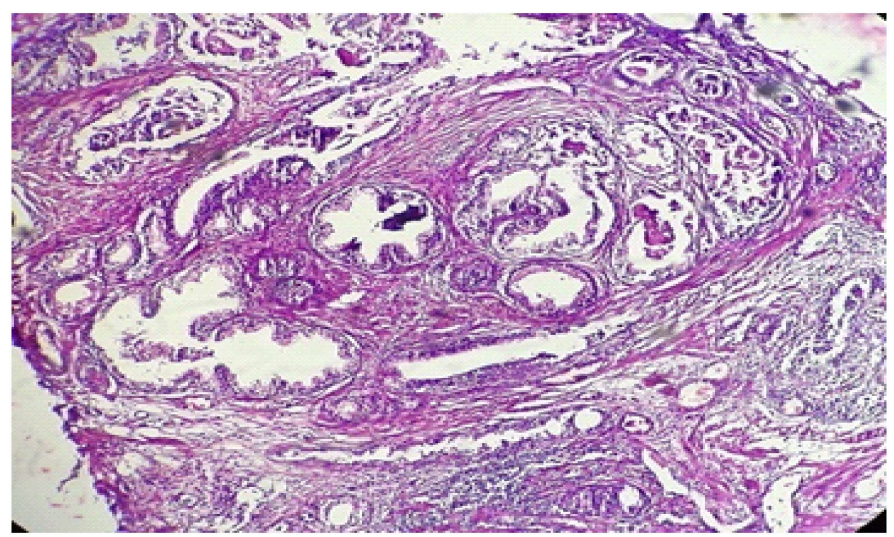

Figure 1 Proliferating acinar cells, intraluminal secretions and chronic inflammatory cells in benign nodular hyperplasia (H \& E 100X)

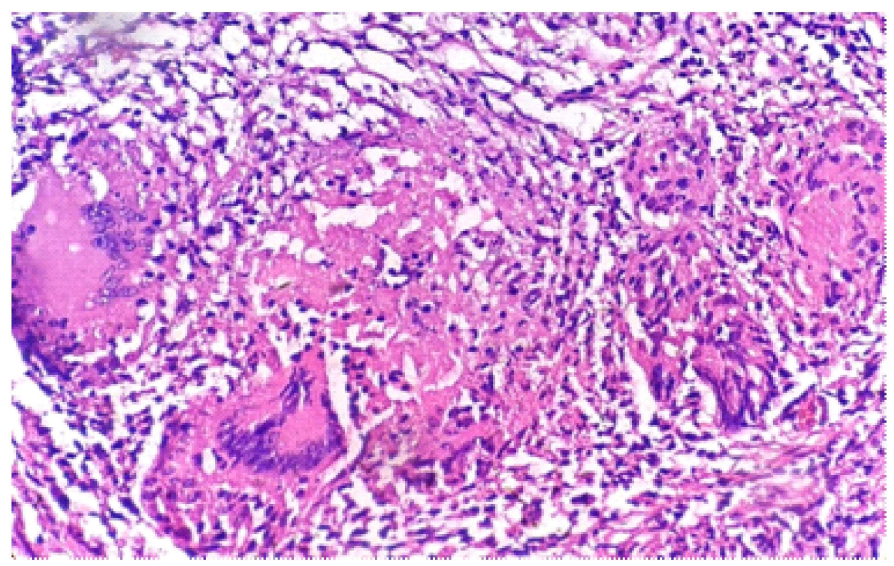

Figure 2 Granulomatous prostatitis (H \& EX 400)

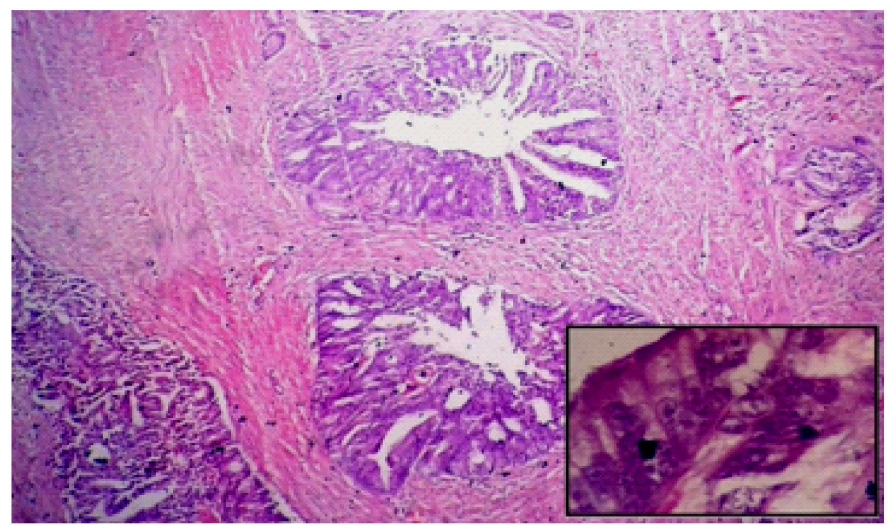

Figure 3 Nuclear stratification in HGPIN (H \& E; 100X), InsetProminent nucleoli in HGPIN (H \& E; 1000X)

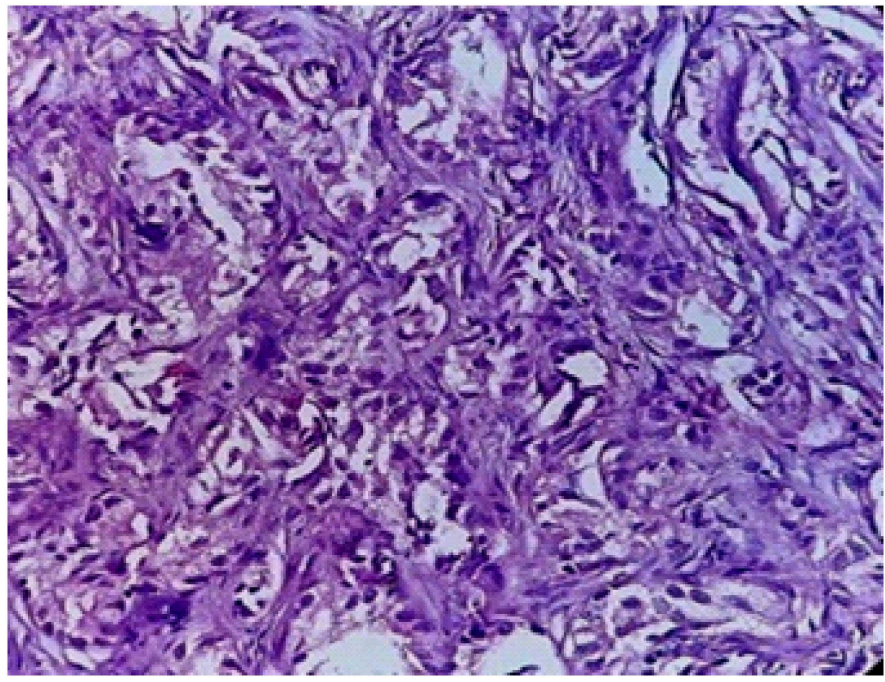

Figure 4 Features of adenocarcinoma of prostate (H \& E: $100 \mathrm{X})$

\section{DISCUSSION}

The objective of this study was to evaluate the serum PSA levels in 71 patients presenting with an enlarged prostate and to evaluate the efficiency of serum PSA to diagnose and differentiate benign from malignant enlargements.

Histologically, it was seen that out of total cases $(\mathrm{N}=71)$, most of the cases were benign, comprising of $59(83.10 \%)$ cases followed by premalignant (HGPIN) and malignant cases comprising of $7(9.85 \%)$ and $5(7.04 \%)$ cases respectively (Table 1). Studies in India and abroad also observed predominance of benign lesions comprising of $74.52 \%$ $94 \%{ }^{7-9}$

Benign lesions comprised predominantly of nodular hyperplasia of prostate (Figure 1) consisting of 45 cases $(63.38 \%)$ which are in concordance with other studies with an incidence of $74.52 \%-79 \%$ (Table 1). Inflammatory lesions including granulomatous prostatitis (Figure 2) are observed in $4.23 \%$ cases which is much higher than the published data of $1.4 \%-2.82 \% .^{10}$

Basal cell hyperplasia comprised of 2(2.82\%) cases of nodular hyperplasia in the present study which is much lower than the published data of $8.2 \% .^{11}$ Most common histomorphological variables observed in this study for benign lesions were papillary infoldings, cystically dilated glands, corpora amylacea and presence of basal cells (Table 2).

High-grade prostate intraepithelial neoplasia comprised of 7 $(9.86 \%)$ cases in the present study which is quite similar to other observations. ${ }^{12}$ In this study, features considered under nuclear atypia were nuclear stratification, nucleomegaly, irregular nuclear contour and prominent nucleoli (Figure 3). Similar morphology with nuclear crowding and stratification has been suggested as a very important histological feature for HGPIN diagnosis on prostate intraepithelial neoplasia. ${ }^{13}$ Other features like single cell layer, central necrosis and mitosis were also seen in 3 (42.86\%), 2 (28.57\%) and 1 (14.29\%) cases respectively (Table 3 ).

Prostatic adenocarcinoma comprised of 5 (7.04\%) cases. 
Out of the 5 cases, $4(5.63 \%)$ cases were acinar type adenocarcinoma (Figure 4$)$ and $1(1.41 \%)$ case was of adenocarcinoma of mixed acinar and ductal type. Published data shows variable incidence from $0.73 \%$ to $24.6 \%$ from different countries. ${ }^{7-9,14}$ One of the malignant cases was of a mixed acinar and ductal type, where there were papillary structures. Some authors described papillary and cribriform architecture as the two most common patterns of ductal carcinoma subtype. ${ }^{15}$

Serum PSA was assessed in all the cases $(\mathrm{N}=71)$ and the findings were divided into 3 categories; $0-4 \mathrm{ng} / \mathrm{ml}, 4-10 \mathrm{ng} /$ $\mathrm{ml}$ and $>10 \mathrm{ng} / \mathrm{ml}$, accordingly, age group and histological diagnosis were correlated ${ }^{3}$. Serum PSA level of 0-4 ng/ml, comprising of $67.61 \%$, followed by $>10 \mathrm{ng} / \mathrm{ml}$ comprising of $16.90 \%$ and then $4-10 \mathrm{ng} / \mathrm{ml}$ comprising of $15.49 \%$ cases were observed in the present study. Gleason score was assessed in all the malignant cases. Gleason score $3+3=6$ was seen in 2 cases, score $3+4=7$ in 1 case, 1 case seen each in acinar type $(4+5=9)$ and mixed acinar and ductal type $(3+5=8)$ of prostate adenocarcinoma.In our study, it was seen that score 6 was more commonly seen.

HPE \& PSA correlation studies: A statistically significant positive correlation was seen between serum PSA and histological diagnosis $(r=0.538, p=0.000)$, benign lesions of prostate had lower serum PSA values and premalignant \& malignant lesions of prostate had higher serum PSA values. In the present study, it was seen that all the benign lesions had a serum PSA level of less than $10 \mathrm{ng} / \mathrm{ml}$; mostly comprising of $0-4 \mathrm{ng} / \mathrm{ml}$, premalignant lesions had a serum PSA level of $11-20 \mathrm{ng} / \mathrm{ml}$ and all the malignant lesions had a serum PSA level of more than $20 \mathrm{ng} / \mathrm{ml}$. It was seen that in most of the benign cases including 44 cases of nodular hyperplasia of prostate, 1 case of nodular hyperplasia of the prostate with basal cell hyperplasia and 3 cases of nodular hyperplasia of the prostate with granulomatous prostatitis had a serum PSA level of less than $4 \mathrm{ng} / \mathrm{ml}$ (Table 4).

A study on serum PSA level reveals that PSA level of $0-4 \mathrm{ng} /$ $\mathrm{ml}$ was significantly associated with benign lesions and values more than $20 \mathrm{ng} / \mathrm{ml}$ was associated with malignant lesions which were similar to the findings of our study. It was seen that nodular hyperplasia of prostate associated with extensive inflammation had a serum PSA level more than $4 \mathrm{ng} / \mathrm{ml}$. Few studies had also found that inflammatory lesions of prostate correlate with low serum PSA levels. ${ }^{16}$ Some researchers claim a good rate of detectable prostate cancer with serum PSA levels of 2.6- $4.0 \mathrm{ng} / \mathrm{ml}^{17-19}$. Therefore, these findings were discordant with our study. A strong correlation between age and histological diagnosis $(r=0.242 *, p=0.042)$ was observed in the present study with benign and premalignant lesions are seen at an earlier age compared to malignant lesions. Similar findings were observed in a study comprising a large number of cases. The present study did not find any correlation between Gleason score and a serum PSA level $(\mathrm{r}=-.258, \mathrm{p}=0.676)$, contrary to the claim by some studies. $^{20,21}$

\section{CONCLUSION}

In this study, an attempt was made to analyze the histomorphological features of prostate biopsies and to further correlate them with serum PSA levels. The study showed that there is a statistically positive correlation between histological diagnosis and serum PSA. In all cases of malignancy, Gleason score was correlated with serum PSA values. However, the present study did not reveal any correlation between the two variables contrary to some published reports.

Acknowledgement: The authors express their sincere thanks to the Chief Medical Director, Dr. (Mrs.) TA Rahman, Rahman Hospitals Pvt. Ltd. for allowing us to carry out the study.

Contribution of authors: (1) The article is original with the author(s) and does not infringe any copyright or violate any other right of any third party. (2) The article has not been published (whole or in part) elsewhere and is not being considered for publication elsewhere in any form, except as provided herein. (3) All author(s) have contributed sufficiently in the article to take public responsibility for it and (4) All author(s) have reviewed the final version of the above manuscript and approved it for publication.

Ethical clearance: Taken.

Conflict of interest: None declared.

Source of funding: None declared.

\section{REFERENCES}

1. Thangaiah JJ, Balachandran K, Photodiode U, Bhat S. Validity of fine needle aspiration cytology in diagnosis of prostatic lesions and correlation with trucut biopsy. NAJ Med Sci 2014;7(2):75-80.

2. Shariat SF, Roehrborn CG. Using biopsy to detect prostate cancer. Rev Urol 2008;10(4):262-80.

3. Ingle SP, Ingle R, Sumana. The efficiency of the serum prostate specific antigen levels in diagnosing prostatic enlargements. J Clin Diag Res 2013 Jan;7(1):82-8.

4. Djavan B, Remzi M, Erne B, Bamberger M. The pathophysiology of benign prostatic hyperplasia. Drugs of Today (Barc Spain: 1998) 2002 Dec;38(12):867-6.

5. Rekhi B, Jaswal TS, Arora B. Premalignant lesions of prostate and their association with nodular hyperplasia and carcinoma prostate. Indian $J$ Cancer 2004;41(2):60-5.

6. Bostwick DG. Prostatic intraepithelial neoplasia(PIN): Current concepts. J Cell Biochem 1992;50:10-9.

7. Josephine A. Clinicopathological study of prostatic biopsies. J Clin Diagn Res 2014;8(9):FC04-6.

8. Mittal BV, Amin MB, Kinare SG. Spectrum of histological lesions in 185 consecutive prostatic specimens. J Postgrad Med 1989;35(3):157.

9. Shirish C, Jadhav PS, Anwekar SC, Kumar H, Buch AC, Chaudhari US. Clinico-pathological study of benign 
and malignant lesions of prostate. Int $\mathrm{J}$ Pharm Biol Sci 2013;3(1):162-78.

10. Mohan H, BalA, Punia RPS, Bawa AS. Granulomatous prostatitis - an infrequent diagnosis. Int $\mathrm{J}$ Urol 2005;12:474-8.

11. Thorson P, Swanson PE, Vollmer RT, Humphrey PA. Basal Cell Hyperplasia in the peripheral zone of the prostate. Mod Pathol 2003 Jan;16(6):598-606.

12. Wills ML, Hamper UM, Partin AW, Epstein JI. Incidence of high-grade prostatic intraepithelial neoplasia in sextant needle biopsy specimens. Urology 1997;49(3):367-3.

13. Brawer MK. Prostatic Intraepithelial Neoplasia: an overview. Rev Urol 2005;7(3):S11-8.

14. Belbase NP, Agrawal CS, Pokharel PK, Agrawal S, Lamsal M, Shakya VC. Prostate cancer screening in a healthy population cohort in eastern nepal: an explanatory trial study. Asian Pac J Cancer Prev 2013;14(5):2835-8.

15. Tantan Liu, Yingmei Wang, Ru Zhou, Haiyang Li, Hong Cheng, Jing Zhang. The update of prostatic ductal adenocarcinoma.China J Cancer Res 2016 Feb;28(1):50-7.

16. Wadgaonkar AR, Patil AA, Mahajan SV, Yengantiwar RP. Correlation of serum prostate specific antigen
(PSA) level in various prostate pathology in elderly men. Int J Basic Appl Med Sci 2013;3(2):274-81.

17. Thompson IM, Pauler DK, Goodman PJ, Tangen CM, Lucia MS, Parnes HL, et al. Prevalence of prostate cancer among men with a prostate-specific antigen level $<$ or $=4.0 \mathrm{ng}$ per milliliter. N Engl J Med 2004 May 27;350(22):2239-46.

18. Gurumurthy D, Maggad R, Patel S. Prostate carcinoma: correlation of histopathology with serum prostate specific antigen. Sci J Clin Med 2015 July;4(1):1-5.

19. Jackson LA, McGrowder DA, Lindo RA. Prostate specific antigen and Gleason Score in men with prostate cancer at a private diagnostic radiology centre in Western Jamaica. Asian Pac J Cancer 2012;13:1453-6.

20. Abdellatif J, Hajji F, Elonodo JC, Ghadouane M, Ameur A. Update the indicator role of serum PSA level and Gleason score of the biopsy for the presence of bony metastases: bone scan findings in a North African ethnic group. J Cancer Sci Ther 2011;03(05).

21. Okada K, Kojima M, Naya Y, Kamoi K, Yokoyama K, Takamatsu T, et al. Correlation of histological inflammation in needle biopsy specimens with serum prostate- specific antigen levels in men with negative biopsy for prostate cancer. Urology 2000;55:892-8. 